\title{
A narrativa da prática como uma estratégia de construção do conhecimento na formação superior em saúde
}

\section{Practice reports as a strategy for knowledge construction in health professional graduation courses}

\author{
Verônica Santos Albuquerque ${ }^{1}$ \\ Carlos Otávio Fiúza Moreira ${ }^{2}$ \\ Suzelaine Tanji ${ }^{3}$ \\ André Vianna Martins ${ }^{4}$
}

\begin{abstract}
RESUMO
O artigo apresenta algumas possibilidades de utilização de narrativas da prática como estratégia de construção do conhecimento na formação de profissionais de saúde, tendo como base a experiência de um grupo de professores (tutores) do Curso de Graduação em Enfermagem do Centro Universitário Serra dos Órgãos (UNIFESO - Teresópolis, RJ). O núcleo da discussão é a relação entre aprendizagem e experiência, a partir das reflexões de John Dewey e David Ausubel. Entre os temas discutidos, destacam-se a valorização da experiência prévia dos estudantes, o trabalho em cenários de prática e a ideia de aprendizagem significativa.

Palavras-chave: educação; educação em saúde; experiência; aprendizagem significativa.
\end{abstract}

1 Enfermeira pela Universidade Federal do Rio de Janeiro (UFRJ). Doutora em Saúde pública pela Escola Nacional de Saúde Pública Sergio Arouca (ENSP-FIOCRUZ). Professora Adjunta do Curso de Graduação em Enfermagem e Medicina do Centro Universitário Serra dos Órgãos (UNIFESO), Brasil. E-mail: veronicatere@gmail.com.

2 Bacharel e Licenciado em Filosofia pela Pontifícia Universidade Católica do Rio de Janeiro (PUC-Rio). Mestre e Doutor em Educação pela PUC-Rio. Professor e pesquisador da Escola Nacional de Saúde Pública Sérgio Arouca (ENSP-FIOCRUZ), Brasil. E-mail: otavio@ensp.fiocruz.br.

3 Enfermeira. Mestre em Enfermagem pela Universidade Federal de Santa Catarina (UFSC). Professora adjunta do Curso de Graduação em Enfermagem e Medicina do Centro Universitário Serra dos Órgãos (UNIFESO), Brasil.

4 Médico veterinário pela Universidade Federal Fluminense (UFF). Mestre em Patologia Veterinária pela UFF. Professor titular dos Cursos de Graduação em Enfermagem, Medicina e Medicina Veterinária do Centro Universitário Serra dos Órgãos (UNIFESO), Brasil. 


\begin{abstract}
This article presents some possibilities for use of practice reports, as a strategy for knowledge construction on health professionals' formation. It was developed based on a group of teachers (tutors) experiences on the Nursing Graduation Course of UNIFESO (Teresópolis, RJ). The discussion focus is the relation between learning and experience, based on John Dewey and David Ausubel reflections. Among the discussed subjects, we highlighted the valorization of previous experiences brought by students, the work on spaces of professional practice and the concept of meaningful learning. Keywords: education; health education; experience; meaningful learning.
\end{abstract}

\title{
Introdução
}

O objeto deste artigo é apresentar uma discussão sobre algumas possibilidades de utilização de narrativas ou relatos da prática como estratégia de construção do conhecimento na formação de profissionais de saúde.

Narrar é uma manifestação que acompanha o homem desde sua origem, podendo ser feita oralmente ou por escrito. Refletir sobre o ato de narrar é quase tão antigo quanto o próprio narrar. Platão e Aristóteles iniciaram, na tradição Ocidental, uma discussão sobre a relação entre o modo de narrar, a representação da realidade e os efeitos sobre os ouvintes e leitores, que vem tendo continuidade até os dias atuais (GANCHO, 1998; LEITE, 1994). A narrativa como objeto da ciência nasceu nas Ciências Humanas, mais especialmente na linguística.

Em seu sentido mais corrente e geral, a narrativa é o nome para um conjunto de estruturas linguísticas e psicológicas transmitidas cultural e historicamente, delimitadas pelo nível do domínio de cada indivíduo e pela combinação de técnicas sócio-comunicativas e habilidades linguísticas - como denominado por Bruner (1991) - e, de forma não menos importante, por características pessoais como curiosidade e paixão (BROCKMEIER; HARRÉ, 2003).

Wittgenstein (1953) e Vigotsky (1987) alertaram sobre o fato de que a linguagem pode ser entendida como um tipo de transformação, ou mesmo de tradução de significados pré-linguísticos em palavras e sentenças. Assim, as narrativas não devem ser concebidas como a apresentação de uma versão externa de entidades mentais particulares, pairando em um tipo de condição pré-semiótica. Apresentar algo como narrativa não significa externalizar algum tipo de realidade interna nem oferecer uma delimitação linguística para essa tal realidade. Ao contrário, narrativas são formas inerentes em nosso modo de alcançar conhecimentos que estruturam a experiência do mundo e de nós 
mesmos. Em outras palavras, a ordem discursiva através da qual nós tecemos nosso universo de experiências emerge apenas como um modus operandi do próprio processo narrativo. Estamos lidando primariamente não com um modo de representação, mas com um modo específico de construção e constituição da realidade, como Bruner (1991) apontou. A fim de estudar esse modo de construção, nós devemos examinar cuidadosamente as maneiras pelas quais as pessoas tentam dar sentido às suas experiências. Elas o fazem, entre outras formas, narrando-as.

No currículo do Curso de Enfermagem do UNIFESO, as narrativas da prática são relatos de experiências dos estudantes, a partir de sua inserção em cenários de práticas de saúde. Tais relatos funcionam como disparadores de discussões e servem para motivar a procura de explicações por parte dos estudantes. O trabalho pedagógico com as narrativas da prática está associado à perspectiva de utilizar metodologias ativas de ensino-aprendizagem, tendo em vista mudanças na formação de profissionais de saúde. No Brasil, essa formação apresenta algumas dificuldades no que se refere ao perfil dos egressos, pois se privilegia a especialização precoce, o uso intensivo de tecnologia e os procedimentos de alto custo; ao mesmo tempo em que se acumulam as necessidades básicas de saúde de grande parte da população brasileira.

A partir do reconhecimento dessas dificuldades e da necessidade de preparar profissionais voltados para atender as necessidades de saúde da população, algumas experiências vêm sendo desenvolvidas em instituições de ensino superior brasileiras. Estas, em geral, estão reconstruindo seus currículos, tendo como referência uma formação para a consolidação do Sistema Único de Saúde (SUS), com destaque para a interdisciplinaridade, a integralidade da atenção à saúde e a responsabilidade social. O movimento de mudança nos Cursos de Graduação em Enfermagem, Medicina e Odontologia do Centro Universitário Serra dos Órgãos (UNIFESO) é uma dessas experiências de mudança curricular. Nesse processo, extinguiram-se as disciplinas e a estruturação curricular passou a operar através de módulos (módulo tutorial e módulo de prática profissional), articulados entre si, conformando um currículo integrado. O módulo tutorial é composto por três espaços de construção do conhecimento: as sessões tutoriais, o estudo autodirigido e as conferências. No módulo de prática profissional, esses espaços se configuram em instrutorias nos laboratórios das ciências básicas e no laboratório de habilidades, além das atividades de integração ensinotrabalho-cidadania.

No módulo tutorial, as sessões se realizam com grupos de até 12 estudantes e um professor (tutor), para o processamento de situações-problema ou narrativas da prática. $\mathrm{O}$ estudo autodirigido caracteriza-se como o tempo no cronograma semanal destinado ao estudo individual dos alunos, quando acontece a 
busca ativa por explicações para as questões construídas pelo grupo a partir de uma situação-problema processada na sessão tutorial. As conferências são atividades programadas semanalmente e podem ser aulas expositivas, filmes, mesas de debate etc. Os temas são sempre articulados com a situação-problema que está sendo processada na semana.

No módulo de prática profissional, as instrutorias nos laboratórios das ciências da saúde (LCS) têm cunho experimental e explicativo e são mediadas por professores, chamados instrutores. Os instrutores dos LCS são especialistas nas respectivas áreas das ciências básicas em que desenvolvem as atividades. Elas acontecem semanalmente e guardam relação com o assunto que está sendo trabalhado no módulo tutorial. As instrutorias no laboratório de habilidades (LH) são mediadas por instrutores, cuja formação é na área da saúde. O objetivo é o desenvolvimento de habilidades articuladas às situações-problema processadas e às demandas das atividades de integração ensino-trabalho-cidadania. Essas habilidades estão relacionadas a destrezas manuais e sensitivas e à comunicação. As atividades de integração ensino-trabalho-cidadania representam o espaço de inserção dos estudantes em cenários de trabalho em saúde, como creches, escolas, unidades básicas e secundárias de saúde, hospitais e outros equipamentos sociais.

\section{Elaboração e processamento das narrativas da prática}

O processamento das narrativas da prática acontece no módulo tutorial, mas há uma articulação fundamental entre esse módulo e o de prática profissional, já que as experiências que geram as narrativas podem e devem ser relacionadas às atividades de integração ensino-trabalho-cidadania desempenhadas pelos estudantes.

Para construção deste artigo, foram selecionadas quatro narrativas da prática produzidas por estudantes do segundo período do Curso de Graduação em Enfermagem do UNIFESO. Além dessas narrativas, apresentamos as questões de aprendizagem construídas e como ocorreu o processamento, identificando aspectos importantes na construção do conhecimento.

O processamento das narrativas da prática, assim como o das situaçõesproblema, ocorre nas sessões tutoriais, com um grupo de estudantes mediados pelo tutor. As situações-problema são construídas por um grupo de docentes que compõem um grupo vinculado à Comissão de Currículo do Curso. Isto é feito para garantir a elaboração de situações-problema que suscitem o desen- 
volvimento das competências indicadas no currículo e uma abordagem no nível de complexidade de cada período. As narrativas da prática, de algum modo semelhantes às situações-problema, são construídas pelos próprios estudantes, a partir de suas experiências nos cenários de integração ensino-trabalho-cidadania. Cada narrativa da prática leva, em média, três sessões tutoriais para seu processamento e construção de sínteses.

Na elaboração de uma narrativa da prática, o grupo constrói coletivamente o relato de uma situação vivida em um dos cenários de integração ensinotrabalho-cidadania em que estão atuando. Geralmente, várias experiências são apresentadas pelos integrantes do grupo. Através do debate, mediado pelo tutor, o próprio grupo busca um consenso, optando por uma narrativa considerada mais significativa e mobilizadora para o estudo. A partir de então, iniciam-se os movimentos de identificação dos problemas e de formulação de possíveis hipóteses. Esse momento inclui a explicitação de ideias, associações iniciais, percepções, sentimentos e valores. Esses movimentos são fundamentais para a mobilização dos conhecimentos prévios dos estudantes e para a identificação das capacidades presentes e das necessidades de aprendizagem de cada estudante e do grupo.

Após o levantamento das diferentes percepções sobre os problemas sugeridos pela narrativa, o grupo formula hipóteses que serão a base para elaboração de questões de aprendizagem, as quais orientam a busca de novas informações. Embora possam ser produzidas ao longo de todo o trabalho, o grupo seleciona as questões consideradas fundamentais e que serão objeto de discussão da sessão tutorial seguinte. Preferência é dada à formulação de questões de aprendizagem que possibilitam associações entre a situação em debate e a realidade.

A procura por novas informações, também chamada de busca ativa, é realizada pelos estudantes da forma e onde considerarem mais adequada. $\mathrm{O}$ Curso oferece um conjunto de referências bibliográficas na forma de livros e revistas científicas, além de estimular o acesso a bancos de dados e bases de publicações indexadas. Para algumas situações, essa busca poderá envolver a coleta primária de dados por meio de entrevistas e visitas de observação. Os espaços de instrutoria também podem ser utilizados na busca por explicações para as questões suscitadas pela narrativa da prática.

As informações trazidas são analisadas criticamente pelo grupo no que se refere ao conteúdo, à relevância e à qualidade das fontes. A construção de novos significados ocorre pelo confronto entre os saberes prévios do grupo e as novas informações e experiências consideradas válidas. A articulação entre esses novos saberes e a narrativa da prática que os desencadeou possibilita e desenvolve competências capazes de serem mobilizadas em outras situações da realidade. 
Esta forma de trabalho pedagógico com as narrativas da prática na formação dos estudantes de Enfermagem no UNIFESO valoriza o pensamento reflexivo. Para Rodgers (2002), o processo reflexivo, caracterizado como um tipo de pensamento atrelado à ação e que demanda uma ação qualificada diferente da rotineira tornou-se um dos elementos mais importantes para se compreender a construção do conhecimento prático-profissional. Além disso, também se tornou o eixo para nortear a aprendizagem da prática, ao propiciar uma maior compreensão das relações que se estabelecem com outras experiências e ideias e, assim, criar uma condição de continuidade da aprendizagem.

Relatos da prática, na qual o estudante ou profissional descrevem e refletem sobre suas ações em determinadas situações, demandam o que Bruner (1997) nomeou de pensamento narrativo, que é um tipo de pensamento trilhado no particular e que se preocupa com as conexões entre os eventos específicos para explicar os motivos. O processo de narrar a própria experiência possibilita ao sujeito reconstruir sua trajetória e lhe oferecer novos sentidos, estabelecendo uma relação dialética entre experiência e narrativa, mediada por processos reflexivos (RODGERS, 2002; CUNHA, 1997).

A narrativa provoca mudanças na forma como as pessoas compreendem a si próprias e aos outros. Tomando-se distância do momento de sua produção, é possível, ao "ouvir" a si mesmo ou ao "ler" seu escrito, que o produtor da narrativa seja capaz, inclusive, de teorizar a própria experiência. Este pode ser um processo profundamente emancipatório em que o sujeito aprende a produzir sua própria formação, autodeterminando a sua trajetória (CUNHA, 1997).

\section{As narrativas}

As narrativas da prática aqui apresentadas foram construídas a partir das experiências de estudantes do segundo período do curso de Enfermagem. São narrativas que podem ser classificadas como descritivas. Para Marcolino e Mizukami (2008), a narração descritiva é o registro dos eventos em que não há justificativa para a ocorrência das ações. Os excertos de narração descritiva se detêm na descrição da situação e de seu contexto, apresentam o desenrolar da trama, mostrando as ações dos personagens envolvidos, sem suas justificativas explícitas.

O segundo período do Curso de Enfermagem faz parte de um ciclo curricular que aborda a dimensão do cotidiano da vida. Ou seja, o enfoque está voltado para indivíduos em cenário de produção de vida e ações integrais em 
saúde. A ênfase do segundo período é a saúde do adolescente. Sendo assim, as narrativas da prática se originam das vivências nos cenários de integração ensino-trabalho-cidadania, que são escolas de ensino médio e organizações de apoio ao adolescente.

Narrativa 01 (Grupo A): Beto, 16 anos, integrante do Programa Municipal de Atendimento ao Jovem, no exame físico, apresentou: Pressão arterial: $150 \times 90 \mathrm{mmHg}$ e pulso fino. $O$ adolescente relatou: intensa prática de esporte (três modalidades esportivas com prática diária) e a avó com diagnóstico de hipertensão arterial. Duas suspeitas de diagnóstico foram levantadas para Beto: hipertensão arterial e arritmia cardíaca.

A partir da narrativa 01, o grupo de estudantes, mediados pela tutora do grupo A, construiu as seguintes questões de aprendizagem: 1) Como é o ritmo cardíaco normal e o que é arritmia cardíaca? 2) Qual é o impacto da prática esportiva no ritmo cardíaco? 3) Quais são os critérios diagnósticos que definem a hipertensão arterial?

Para o processamento das questões apresentadas, o grupo recorreu à pesquisa bibliográfica e ao agendamento de instrutoria de anatomofisiologia sobre sistema cardiovascular, além de instrutoria no laboratório de habilidades sobre eletrocardiograma.

Dentre as fontes bibliográficas consultadas, destacaram-se livros de anatomia, fisiologia, clínica médica, tratados de enfermagem e literatura específica sobre eletrocardiograma. Além desses livros, os estudantes recorreram a manuais do Ministério da Saúde.

$\mathrm{Na}$ instrutoria de anatomofisiologia, observaram peças anatômicas e discutiram com o instrutor o sistema de condução elétrica do coração. No laboratório de habilidades, relacionaram os fenômenos de geração e condução do impulso elétrico cardíaco aos traçados do eletrocardiograma, identificando o ritmo sinusal (normal) e arritmias simples, como a bradicardia e a taquicardia.

Durante o processamento das questões na sessão tutorial, as informações trazidas da busca bibliográfica e das instrutorias foram sendo discutidas, relacionadas, sistematizadas e consolidadas como conhecimento construído pelo grupo.

Narrativa 02 (Grupo A): Em visita domiciliar à família de um adolescente, interno do Centro de Recurso Integrado e Atendimento ao Menor, conhecemos o seu pai, o Sr. M.S.S, 42 anos, atualmente desempregado, que relatava atividade laboral como pedreiro há quatro anos. Ele apresentava lesões avermelhadas e descamativas no tórax anterior e posterior, face, cabeça e membros torácicos. Relatava, ainda, prurido nas lesões e consumo diário de álcool. O problema foi encarado como possível "alergia ao cimento" durante algum tempo. Mas, após atendimento na Unidade de Saúde da Família, foi diagnosticado pelagra. O Sr. M.S.S foi medicado, mas os sintomas não regrediram. 
A partir da narrativa 02 , o grupo de estudantes, mediados pela tutora do grupo A, levantou algumas hipóteses e construiu as seguintes questões de aprendizagem: 1) Como se desenvolve o mecanismo da alergia? 2) O que é pelagra? Quais são seus sinais e sintomas? Como é o tratamento? 3) Por que o tratamento do Sr. M.S.S. não tem sucesso? Há relação entre pelagra e alcoolismo?

Para o processamento das questões apresentadas, o grupo recorreu à pesquisa bibliográfica. Dentre as fontes bibliográficas consultadas, destacaram-se livros de imunologia, patologia e clínica médica. Além desses livros, os estudantes recorreram à literatura sobre nutrição e sobre alcoolismo.

Após o entendimento que a pelagra é uma doença causada pela falta de niacina ou do aminoácido essencial triptofano, foi agendado um encontro com um estudante monitor de bioquímica. Tanto no espaço da monitoria, quanto da tutoria, foi problematizada a relação da pelagra e seu tratamento com o alcoolismo. Compreendeu-se, então, a partir da busca bibliográfica, que o alcoolismo crônico, a desnutrição e a deficiência absortiva associadas predispõem à pelagra e interferem na terapêutica. Logo, apesar do tratamento instaurado, os sintomas não iriam regredir. Assim, os estudantes construíram e implementaram um plano de cuidados individual, além do que vêm organizando uma rede de suporte para o Sr. M.S.S., que conta com a equipe da Unidade de Saúde da Família, visando o tratamento do alcoolismo.

Nessa narrativa da prática ficou clara a articulação de conteúdos das bases biológicas e sociais. Além disso, o problema do Sr. M.S.S. foi fundamental para qualificar os planos de cuidado e de intervenção da equipe de saúde envolvida.

Narrativa 03 (Grupo B): R.R.O., 14 anos, estudante do ensino médio de uma escola municipal de Teresópolis, deixou de frequentar as aulas desde abril por motivo de internação. $O$ adolescente foi hospitalizado por conta de episódios repetidos de convulsões e alterações visuais. A suspeita era neurocisticercose, mas R.R.O. faleceu antes da conclusão diagnóstica. A família autorizou a necropsia, a qual revelou um tumor cerebral como causa do óbito.

A partir das hipóteses deflagradas pela problematização da narrativa 03 , o grupo de estudantes, mediados pela tutora do grupo B, construiu as questões de aprendizagem: 1) Como se desenvolve a neurocisticercose? Como se manifesta, se trata e se previne? 2) Há relação entre neurocisticercose e consumo de carne? 3) Como se desenvolvem os tumores cerebrais? 4) Quais as indicações para realização de uma necropsia? Como ela é realizada? Quem pode autorizá-la?

$\mathrm{Na}$ narrativa da prática 03 , o grupo recorreu à pesquisa bibliográfica, com destaque para os livros de anatomia, fisiologia, patologia, parasitologia e medicina legal. Os estudantes buscaram, ainda, instrutoria de anatomofisiologia para revisão dos aspectos de normalidade do sistema neurológico. 
O grupo se sentiu motivado para assistir uma sessão de necropsia. Para tal, procuraram o professor da disciplina de Medicina Legal do Curso de Medicina. O professor, que também atua como legista em Teresópolis, levou o grupo de estudantes e a tutora para participarem de uma necropsia, antes do encerramento da narrativa da prática. Esta vivência trouxe um enriquecimento à construção de conhecimento do grupo, que extrapolou os aspectos técnicos dos procedimentos médico-legais, trazendo à discussão as dimensões éticas e humanísticas.

Narrativa 04 (Grupo C): Ao iniciarmos as atividades de IETC no Colégio Estadual Presidente Bernardes, encontramos uma estudante de 17 anos gestante. Atualmente, ela está com 27 semanas de gestação e realiza pré-natal de altorisco no Centro Materno-Infantil. Na anamnese, a adolescente nos relatou que estava com "pressão alta" depois de engravidar. Ela faz uso de medicação anti-hipertensiva e dieta. Estamos acompanhando a evolução da gestação e realizando atividades educativas.

A partir da narrativa 04, o grupo de estudantes, mediados pelo tutor do grupo C, construiu as seguintes questões de aprendizagem: 1) Quais são as repercussões da gravidez na adolescência? 2) O que é o pré-natal de alto-risco? Em que casos o pré-natal de alto-risco é realizado? Qual é a diferença para o pré-natal de baixo risco? 3) Como ocorre hipertensão arterial na gravidez e quais são as suas consequências?

O grupo realizou pesquisa bibliográfica em livros de ginecologia e obstetrícia, além das diversas publicações do Ministério da Saúde sobre adolescência, pré-natal e gestação de risco.

No processamento da questão sobre as repercussões da gravidez na adolescência, os estudantes abordaram tanto os impactos biológicos, incluindo as intercorrências clínicas para a mãe adolescente e seu concepto, quando os sociais, como o aborto ilegal, a evasão escolar, a maior dificuldade de inserção no mercado de trabalho e a desestruturação familiar.

Além da pesquisa em literatura especializada, os estudantes realizaram visita ao Centro Materno-Infantil, unidade de saúde de Teresópolis de atenção secundária, onde são realizadas consultas pré-natais para gestantes de alto-risco. Lá, realizaram entrevista com a enfermeira responsável pelo serviço sobre as questões que estavam estudando. Na sessão de tutoria, compararam e refletiram sobre o material da entrevista e a bibliografia pesquisada.

A sistematização dos conhecimentos construídos no módulo tutorial qualificou a intervenção, em termos de cuidados e de educação para saúde, realizada pelos estudantes de enfermagem junto à adolescente no espaço da escola. 


\section{As narrativas e a experiência}

A prática profissional configura um encontro entre o sujeito da aprendizagem e a realidade social. Por isso, é importante criar nos processos de formação em saúde oportunidades de observar as situações e sistematizá-las em narrativas que favoreçam uma reflexão sobre a prática. $\mathrm{O}$ trabalho pedagógico com narrativas da prática permite inferir a possibilidade de construção de novos significados a partir de experiências reais vivenciadas pelos estudantes.

Um referencial importante para reflexão sobre as narrativas da prática na formação profissional é a relação entre aprendizagem com a experiência, um dos núcleos da obra do filósofo da educação John Dewey (1859-1952). Para Dewey, a educação pode ser definida como uma reconstrução da experiência (MOREIRA, 2002). Neste sentido, o desenvolvimento da capacidade dos estudantes e do professor de refletir sobre o vivido, reconstruindo-o, deveria ocupar um lugar central nos processos de educação escolar. Experiência pode ser compreendida aqui como interações do indivíduo em determinadas situações no mundo, que incluem outros indivíduos, o meio físico e social. Assim, a experiência que se incorpora nos processos de ensino-aprendizagem diz respeito, em última instância, à memória, à história dos alunos.

Cunha (2002) entende que o conceito de experiência que se encontra na concepção deweyana de educação constitui o elemento fundamental do método para se aprender, pois o ato de pensar começa justamente com a experiência, não sendo algo que a ela se sobrepõe. O educando deve ser posto no interior de uma situação que o leve a tentar fazer alguma coisa; o resultado desse esforço fará com que algo novo se acrescente ao aprendiz. Ao pretender ensinar, o professor não deve nunca dispensar a experiência pessoal prévia dos alunos relacionada ao assunto em questão; deve dar aos estudantes algo "para fazer" e não algo "para aprender", o que significa colocá-los em ação de maneira que possam refletir sobre as relações envolvidas no objeto ou na situação de estudo.

Enfim, desta perspectiva, pode-se afirmar o seguinte: há uma conexão orgânica entre educação e experiência; a educação se consuma através da experiência. Uma experiência (positiva ou não) se prolonga em experiências que se sucedem. A educação escolar, como todos os processos de socialização, é produtora de experiência; há que se pensar sobre as características (qualidade) da experiência por que se passa na escola.

É nesse contexto que situamos a construção das narrativas da prática como parte da experiência dos estudantes, de situações vividas com pessoas e coletividades nos cenários de integração ensino-trabalho. Cabe ressaltar que 
esses cenários, representados em geral por comunidades, serviços de saúde e equipamentos sociais, estão no contexto da vida cotidiana. Como indica John Dewey (1959, p. 168):

Se tivermos em vista despertar a inteligência e o pensamento e não meras aquisições de palavras, a primeira apresentação de qualquer matéria na escola deve ser o menos acadêmica ou escolástica possível. Para compreender o que significa uma experiência ou uma situação empírica, o espírito precisa evocar a espécie de situação que apresenta naturalmente interesse, pondo em jogo a atividade.

Este postulado indica que os educandos devem ser colocados inicialmente diante de situações que despertem interesse e necessitem da resolução de problemas, que funcionem como disparadores da aprendizagem. Questões estimulam e orientam a observação e o estabelecimento de relações entre as coisas, de modo a resultar em conclusões e provas relevantes sobre a natureza do tema estudado.

Para Dewey (1959; 1976), não há aprendizagem genuína em processos divorciados da experiência, em que se memorizam fatos sem perceber relações, gerando um conhecimento destituído de significado para o ser que aprende. $\mathrm{O}$ sentido do processo é vital para que uma experiência seja educativa. Sem isso, o estudante não toma o processo de aprendizagem como algo relacionado a si. $\mathrm{O}$ estudo se apresenta como uma obrigação sua enquanto aluno, como uma exigência da escola, do professor, como algo útil para obtenção de bons resultados nos exames, mas que não se relaciona com a sua vida.

A proposta de formulação das narrativas ou relatos da prática pelos estudantes procura atender também à prerrogativa da identificação do problema como autêntico e relevante para o seu estudo e para construção da competência profissional, aproximando a sistematização do conhecimento do seu significado prático.

Nesse sentido, John Dewey já se preocupara com a crescente formalização da educação e o consequente isolamento da escola da experiência dos alunos, especialmente nos ambientes escolares em que é requerida a transposição dos saberes sob a forma de símbolos. É preciso evitar incorrer no erro de tornar os conteúdos desarticulados das ações e do contato com as coisas que eles significam. Além disso, os espaços acadêmicos devem se apropriar de instrumentos para o desenvolvimento de atividades cooperadoras e conjuntas, pois esse é um 
tipo de experiência fundamental para a construção de uma sociedade democrática (MOREIRA, 2002). A hipótese que sustenta esta visão é a seguinte:

Só se consegue mentalidade social dedicando-se os homens à atividade conjunta, na qual o uso de materiais e utensílios, por parte de uma pessoa, se relaciona conscientemente com o uso que outras pessoas fazem de suas aptidões e recursos (DEWEY, 1959, p. 42).

Se os livros e a teoria podem fazer algo neste sentido, o que Dewey propunha era que as escolas desenvolvessem atividades nas quais os alunos tomassem parte conjuntamente, para que pudessem experimentar o sentido social de suas ações. Exemplo: experiência de trabalho em equipe. Aprender a resolver problemas, aprender a trabalhar junto e aprender a resolver problemas em conjunto são lemas deweyanos. Contudo, as escolas acabam por valorizar um "espírito livresco e pseudo-intelectual" em detrimento de um "espírito social", quando veem o aprendiz como um indivíduo isolado (CUNHA, 2002).

Enfim, as narrativas da prática criam a possibilidade de levar a experiência individual e coletiva ao estágio em que a função reflexiva estabelece relações entre ações e consequências, desenvolvendo uma visão prospectiva. Trata-se de reorganizar a experiência pelo pensamento, transformando a qualidade dessa experiência.

\section{As narrativas e a aprendizagem significativa}

Outro referencial interessante para reflexão sobre a narrativa da prática na formação profissional é o da aprendizagem significativa, descrita por Ausubel et al. (1978) como um processo pelo qual uma nova informação se relaciona, de maneira substantiva e não arbitrária, a um aspecto relevante da estrutura cognitiva do indivíduo. Destacam-se as repercussões das experiências educativas prévias sobre a assimilação do conhecimento novo. Nesse processo, a nova informação interage com uma estrutura de conhecimento específica chamada de subsunçor. O subsunçor é um conceito, uma ideia ou uma proposição já existente na estrutura cognitiva do aprendiz, que ancora a nova informação, de modo que esta adquira significado para o indivíduo. 
Duas condições importantes para a ocorrência da aprendizagem significativa são: um material potencialmente significativo e a disposição do aprendiz para relacionar a nova informação à sua estrutura cognitiva (AUSUBEL et al., 1980). Essas duas condições parecem favorecidas com a construção e processamento de narrativas ou relatos da prática. A condução das sessões tutoriais auxilia na identificação de temas significativos que funcionariam como subsunçores. Além disso, as questões de aprendizagem podem promover motivação necessária no estudante para a continuidade do processo.

Cabe discutir, então, a postura pró-ativa do estudante, fundamental ao processo de busca de novas informações. Como visto nos relatos de processamento das narrativas, várias são as estratégias utilizadas pelos estudantes: pesquisa bibliográfica, agendamento de instrutoria e monitoria, participação em sessão de necropsia, entrevista com profissional de saúde de serviço especializado, entre outras.

O gerenciamento do seu próprio aprendizado é um comportamento que precisa ser estimulado nos estudantes. Perrenoud (2002) propõe essa discussão quando lembra que parte dos estudantes prefere absorver saberes a refletir. De uma forma geral, essa postura mais passiva, que "os habituou a fazer sem questionar muito", ainda está presente em suas formações até a universidade. Logo, eles podem resistir ou ter dificuldade no novo processo de ensino-aprendizagem, que lhes exige maior envolvimento. Nesse sentido, as narrativas da prática podem auxiliar os estudantes na tomada de uma postura mais ativa e autônoma.

\section{Considerações finais}

Até o presente momento, a experiência pedagógica no Curso de Enfermagem do UNIFESO tem mostrado que as situações-problema e as narrativas da prática são potentes estratégias de construção do conhecimento. Por um lado, as situaçõesproblema, formuladas pelas comissões de currículo, visam articular conteúdos pré-definidos; por outro, as narrativas da prática, construídas pelos estudantes a partir de suas situações vividas (experiência), ampliam a percepção da própria realidade e servem para dar sentido prático ao conhecimento.

$\mathrm{O}$ trabalho com as narrativas da prática requer o desenvolvimento e a expansão da capacidade de observação, de registro e de interpretação de fatos. Requer, ainda, a caracterização dos atores envolvidos na situação e de suas perspectivas, recursos e interesses. A narrativa estimula a curiosidade dos estudantes que avaliarão a sua relevância e sua pertinência em relação às necessidades de aprendizagem do grupo. 
O trabalho com as narrativas da prática também vem sendo motivador para os professores. Sua utilização, no contexto das metodologias ativas de ensino-aprendizagem, tem contribuído para a mudança de postura dos docentes. Essa mudança inclui o exercício de um trabalho reflexivo com os estudantes e a necessidade de o professor pesquisar, acompanhar e colaborar no aprendizado crítico dos educandos. As narrativas frequentemente colocam o professor diante de situações novas, desconhecidas e imprevistas, o que demanda um processo de reconstrução do conhecimento verdadeiramente compartilhado entre discentes e docentes.

Assim, essa experiência do Curso de Enfermagem mostra que a sistematização da experiência da prática é estratégia importante para o desenvolvimento de atributos que possibilitam uma aprendizagem consistente. Por conseguinte, o que se espera é que os profissionais em formação sejam capazes de mobilizar em suas práticas as capacidades desenvolvidas, conformando, assim, a articulação teoria-prática e a construção de competência para a ação.

Enfim, o que se pretende com a formalização de espaços para a construção e processamento das narrativas da prática no módulo tutorial do Curso de Graduação em Enfermagem do UNIFESO se aproxima da proposta de Pérez Goméz (1992), que fala do diálogo entre a prática vivida e as construções teóricas formuladas nesta e sobre estas vivências. A reflexão é um modo de fazer reviver a experiência com a intenção de se aprender a partir dela, em que se desenvolvem novas compreensões e capacidade de juízo crítico.

\section{REFERÊNCIAS}

AUSUBEL, D.; NOVAK, J.; HANESIAN, H. Educational psychology: a cognitive view. 2.ed. New York: Holt Rinehart and Winston, 1978.

AUSUBEL, D.; NOVAK, J.; HANESIAN, H. Psicologia educacional. Rio de Janeiro: Interamericana, 1980.

BROCKMEIER, J.; HARRÉ, R. Narrativa: problemas e promessas de um paradigma alternativo. Psicologia: Reflexão e Crítica, Porto Alegre, v.16, n.3, 2003.

BRUNER, J.S. Atos de significação. Porto Alegre: Artes Médicas, 1997. 
BRUNER, J.S. The narrative construction of reality. Critical Inquiry, v.17, p.1-21, 1991.

CUNHA, M.I. Conta-me agora! As narrativas como alternativas pedagógicas na pesquisa e no ensino. Rev. Fac. Educ., São Paulo, v. 23, n. 1-2, 1997. Disponível em: $<$ http://www.scielo.br/scielo.php?script=sci_arttext\&pid=S01 0225551997000100010\&lng=en\&nrm=iso $>$. Acesso em: 31/03/2009.

CUNHA, M.V. John Dewey: uma filosofia para educadores em sala de aula. 4.ed. Petrópolis: Vozes, 2002.

DEWEY, J. Democracia e educação. São Paulo: Editora Nacional, 1959.

DEWEY, J. Experiência e educação. São Paulo: Editora Nacional, 1976.

GANCHO, C.V. Como analisar narrativas. 5.ed. São Paulo: Ática, 1998.

LEITE, L.C.M. O foco narrativo. 7.ed. São Paulo: Ática, 1994.

MARCOLINO, T.Q.; MIZUKAMI, M.G.N. Narrativas, processos reflexivos e prática profissional. Interface - Comum. Saúde Educ., Botucatu, v.12, n.26, p.541-547, 2008.

MOREIRA, C.O.F. Entre o indivíduo e a sociedade: Um estudo da filosofia da educação de John Dewey. Bragança Paulista: EDUSF, 2002.

PÉREZ GOMÉZ, A. O pensamento prático do professor: a formação do professor como profissional reflexivo. In: NÓVOA, A. Os professores e a sua formação. Lisboa: Dom Quixote, 1992. p.93-114.

PERRENOUD, P. A prática reflexiva no oficio de professor. Porto Alegre: Artes Médicas, 2002.

RODGERS, C. Defining reflection: another look at John Dewey and reflective thinking. Teach. Coll. Rec., v.104, n.4, p.842-866, 2002.

VIGOTSKY, L.S. Thinking and speech. New York: Plenum, 1987.

WITTGENSTEIN, L. Philosophical investigation. Oxford: Blackwell, 1953.

Texto recebido em 27 de janeiro de 2009 .

Texto aprovado em 04 de março de 2009. 